\title{
AVALIAÇÃO TÉCNICA E AMBIENTAL DA INJEÇÃO DA CASCA DA MORINGA OLEIFERA EM ALTOS-FORNOS A COQUE
}

\author{
Alex Milton Albergaria Campos ' \\ Paulo Santos Assis ${ }^{2}$ \\ Kátia Monteiro Novack '
}

\section{Resumo}

A Moringa oleifera é conhecida como a árvore da vida por suas inúmeras aplicações nas indústrias farmacêutica, cosmética e nutricional. Seu produto mais nobre é o óleo, que para ser extraído é necessário descascar a semente, na qual são gerados resíduos sem valor agregado. $O$ uso da casca da semente de moringa oleifera tem efeitos ambientais e econômicos positivos como fontes renováveis de combustível. Em relação à questão ambiental, pode-se dizer que os gases de efeito estufa são emitidos, mas a quantidade é a mesma produzida pelo processo de decomposição natural. Além disso, durante $\mathrm{o}$ crescimento, quantidades de $\mathrm{CO}_{2}$ são consumidas na fotossíntese, o que pode contribuir no balanço ao analisar a emissão desses gases na queima da casca. Neste trabalho foi caracterizada a casca da semente de moringa oleifera e avaliado seu uso na injeção de em altos-fornos. Os resultados iniciais mostram que este material tem uma boa taxa de combustão, altos voláteis e conteúdo de hidrogênio. Apesar de o teor de carbono e o poder calorífico serem menores que os do carvão mineral, é possível utilizar $40 \%$ da casca na injeção na mistura de carvão, reduzindo as emissões de $\mathrm{CO}_{2}$ no processo.

Palavras-chave: Biomassa; Moringa oleifera; Injeção de materiais pulverizados; Siderurgia; $\mathrm{PCl}$.

\section{TECHNICAL AND ENVIRONMENTAL ASPECTS OF USING MORINGA OLEIFERA HUSK IN COKE BLAST FURNACE INJECTION}

\begin{abstract}
Moringa oleifera is known as the tree of life for its numerous applications in the pharmaceutical, cosmetic and nutritional industries. To extract the oil it is necessary to peel the seed, which waste doesn ' $t$ have value. The husk has some chemistry properties that are interesting to use in the energy generation. Regarding the environmental issue, greenhouse gases are emitted, but the amount is the same as that produced by the process of natural decomposition. In addition, during growth, quantities of $\mathrm{CO}_{2}$ are consumed in the photosynthesis, which can contribute in the balance when analyzing the emission of these gases in the husk burned. This study aims at characterizing the husk from moringa oleifera seed and evaluating its use as a pulverized material injection for the blast furnace. Initial results show that this material has a good combustion rate, high volatiles and hydrogen content. Despite the carbon content and calorific value been lower than coal, it is possible to use $40 \%$ of the husk in the injection with the coal mixture, reducing $\mathrm{CO} 2$ emissions in the injection process. Keywords: Biomass; Moringa oleifera; Blast furnace injection; Ironmaking; PCI.
\end{abstract}

\section{INTRODUÇÃO}

A Moringa oleifera é uma árvore versátil, que se adapta bem a solos com baixa umidade e climas quentes, com inúmeras aplicações na indústria farmacêutica, cosmética, alimentícia e outras. Seu óleo tem grande potencial não apenas para a produção de cosméticos e medicamentos, mas também para a produção de biodiesel [I].

Um uso inexplorado é gerar energia, no caso desta pesquisa, para a produção de ferro gusa em siderúrgicas. Ao extrair o óleo, alguns resíduos são gerados, tais como a

\footnotetext{
I Programa de Pós-graduação em Engenharia de Materiais - REDEMAT, Universidade Federal de Ouro Preto - UFOP, Ouro Preto, MG, Brasil. E-mail: alexcampos88@yahoo.com.br

${ }_{2}^{2}$ Programa de Pós-graduação em Engenharia de Materiais - REDEMAT, Escola de Minas de Ouro Preto - EM, Universidade Federal de Ouro Preto UFOP, Ouro Preto, MG, Brasil

${ }_{3}^{3}$ Programa de Pós-graduação em Engenharia de Materiais-REDEMAT, Instituto de Ciências Exatas e Biológicas- ICEB, Universidade Federal de Ouro Preto-UFOP, Ouro Preto, MG, Brasil
} 
casca da semente e os resíduos após a extração mecânica ou por solvente das sementes descascadas. Esses resíduos têm grande potencial para gerar energia para processos como a injeção de materiais pulverizados em alto-forno [2].

O processo de injeção de materiais pulverizados de alto-forno é uma técnica que se consolidou nas siderúrgicas em meados do século passado e hoje é conhecida mundialmente, sendo aplicada em mais de 400 altos-fornos em todo o mundo. Neste processo, o combustível é injetado no alto-forno pelas ventaneiras, localizadas na parte inferior do reator, fornecendo energia e gases redutores para o processo de obtenção de ferro gusa, que é a matéria-prima básica para a produção de aço. A principal vantagem deste processo é reduzir o combustível sólido carregado no topo do forno como coque e carvão vegetal [3]. O combustível mais comumente usado no processo de injeção é o carvão mineral, que é um combustível fóssil não renovável. Esse consumo de carvão é o maior responsável pelas emissões de $\mathrm{CO}_{2}$ nas usinas siderúrgicas. Além disso, em alguns países, como o Brasil, não há reservas de carvão com a qualidade desejada para a siderurgia [4]. Porém, é importante lembrar que trabalhos utilizando carvão oriundo do sul do Brasil foram realizados na UFRGS mostrando a viabilidade técnica do seu uso não só na injeção de materiais pulverizados no alto-forno como também na produção de coque metalúrgico [5].

Este trabalho tem como objetivo caracterizar a casca da semente da moringa oleifera, que é um resíduo do processo de extração de óleo, para ser utilizada como combustível juntamente com o carvão mineral nos altos-fornos. Serão apresentadas análises químicas e térmicas da casca da semente da moringa, as quais serão comparadas com as propriedades dos carvões minerais comumente utilizados no processo de injeção. Finalmente, uma pequena análise das emissões de $\mathrm{CO}_{2}$ será mostrada. Será possível perceber que é possível substituir $40 \%$ do carvão pela casca de sementes da moringa no processo, reduzindo as emissões de gases de efeito estufa.

\section{METODOLOGIA}

Os materiais utilizados nesta pesquisa foram a casca da semente da Moringa oleifera e o carvão mineral comumente utilizado na injeção em altos-fornos. A casca foi secada previamente a $110^{\circ} \mathrm{C}$ por I hora e meia, em seguida foi triturada e peneirada sendo recolhido e usado a fração passante em 200\#. O carvão foi recebido pronto para as analises.

Foi realizada a análise imediata para determinar a quantidade de cinzas, materiais voláteis, umidade e por diferença, o carbono fixo. Esta análise foi realizada no laboratório de química analítica do departamento de química da Universidade Federal de Ouro Preto de acordo com ASTM D3 I 72 a D3 I 75 para carvão e ASTM DI I 02, E870 a E872 para biomassa [6].

A análise elementar foi feita no INPE (Instituto Nacional de Pesquisas Espaciais) usando um equipamento Perkin Elmer que forneceu o conteúdo de carbono, hidrogênio, nitrogênio, enxofre e, por diferença, o conteúdo de oxigênio. O Poder calorífico também foi realizado no INPE utilizando um calorímetro adiabático IKA C200, neste teste foi possível obter poder calorífico superior.

O teste de combustão para determinação da taxa de combustão foi realizado no laboratório de simulação de injeção de materiais pulverizados da Universidade Federal de Ouro Preto. $O$ teste foi feito com os materiais puros e também com mistura entre os dois materiais.

No equipamento apresentado na Figura I o material é inserido no porta amostra onde é carreado para o forno 2 pelo oxigênio pré-aquecido no forno I. Após a queima do material (milésimos de segundos) o gás é coletado e analisado no ORSAT, onde por reação química é possível determinar a quantidade de $\mathrm{CO}, \mathrm{CO}_{2}$ e $\mathrm{O}_{2}$.

Enfim, com os dados destas analises é possível calcular a taxa de combustão utilizando a Equação I [7]:

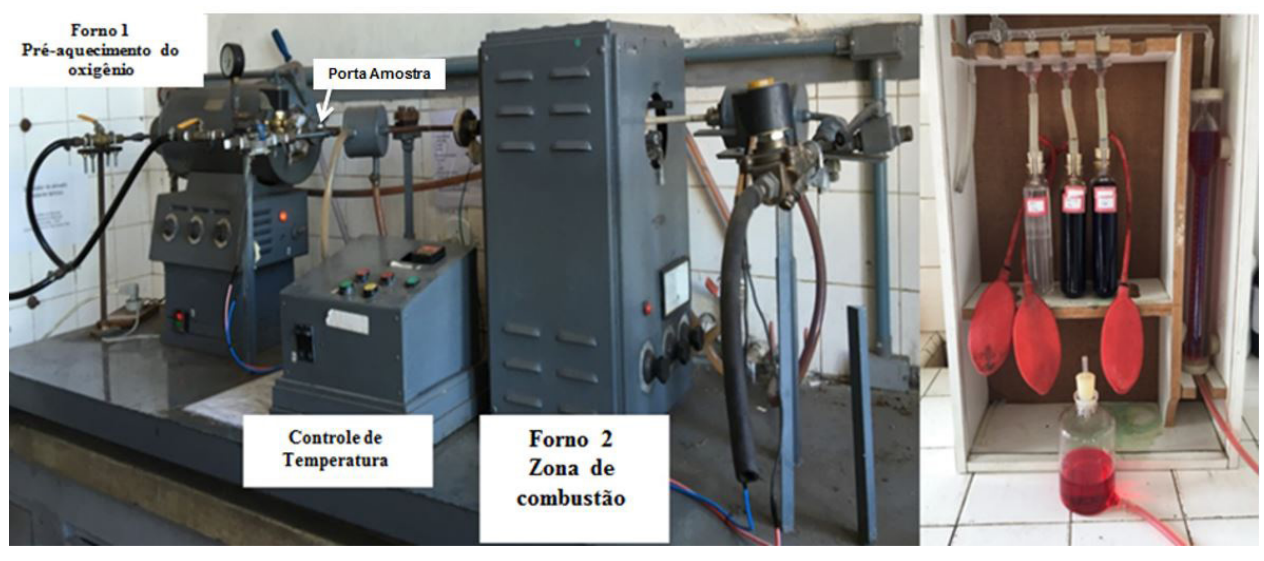

Figura I. Simulador de injeção em altos-fornos e ORSAT para a análise dos gases. 


$$
C R=\frac{K .\left(\% \mathrm{CO}+\% \mathrm{CO}_{2}\right) \cdot n}{\left[\frac{m a . \% \mathrm{Cf}}{1200000}-\frac{n g . \% \mathrm{CH}_{4}}{100}\right]}
$$

onde:

CR é a taxa de combustão; $K$ é uma constante relativa aos parâmetros e condições da simulação; $m_{a}$ é a massa de carbono injetada na amostra; $n_{g}$ é o número de moles de gás após o teste; \% $\mathrm{C}_{\mathrm{f}}$ é a porcentagem de carbono fixo da amostra.

A taxa de combustão nada mais é que a eficiência de combustão que mostra, simplesmente, o quanto este material é capaz de queimar na zona de combustão do alto-forno, liberando gases e fornecendo energia para o processo.

Outra forma de calcular a eficiência de combustão é através do burnout, que é obtido a partir da relação entre o teor de cinzas dos materiais que entraram no reator (forno 2) com o teor de cinzas dos chars coletados após o ensaio [8].

As análises imediata e elementar, assim como o poder calorífico foram realizadas em triplicata. $O$ teste de combustão foi realizado em duplicata, simulando taxas de injeção de 80,100 e $150 \mathrm{~kg}$ de material injetado por tonelada de ferro gusa produzido pelo alto-forno.

Para o cálculo das emissões de $\mathrm{CO}_{2}$, foi Equação 2 [9]:

$$
\mathbf{E C O}_{2}=(\text { Conteúdo de Carbono }(\mathrm{kg}) \times 44) / 12
$$

\section{RESULTADOS E DISCUSSÃO}

Após as análises, os resultados foram anotados e mostrados abaixo.

A Tabela I mostra os resultados da análise imediata, elementar e poder calorífico para a casca de sementes da moringa oleifera e para o carvão mineral.

É possível notar que a casca da semente da moringa possui menor teor de cinzas, carbono, carbono fixo, nitrogênio e enxofre. Em contraste, o conteúdo de voláteis, hidrogênio e oxigênio são maiores. O poder caloríicico do carvão mineral também é maior que o da casca da semente da moringa.

Um fato importante é a grande quantidade de material volátil na casca, mais que o dobro do conteúdo de carbono. Materiais com alto teor de voláteis apresentam

Tabela I. Comparação das propriedades da casca da moringa com o carvão mineral

\begin{tabular}{lcc}
\hline \multicolumn{1}{c}{ Propriedades } & Casca da Moringa & Carvão Mineral \\
\hline \%Cinzas & 2,36 & 13,45 \\
\%Material Volátil & 76,60 & 24,13 \\
\% Carbono Fixo & 22,00 & 62,40 \\
\%Carbono & 48,84 & 80,24 \\
\%Hidrogênio & 6,27 & 3,80 \\
\%Nitrogênio & 0,93 & 1,54 \\
\%Oxigênio & 43,96 & 14,42 \\
\%Enxofre & 0,83 & 0,88 \\
Poder Calorífico (kJ/g) & 20,34 & 31,40 \\
\hline
\end{tabular}

maior combustibilidade [10]. Este tipo de material é desejado para altas taxas de injeção, devido o curto tempo de permanência deste material na zona de combustão do alto-forno. No entanto, um alto teor de voláteis aumenta o volume de gases gerados, aumentando a instabilidade de carga e degradação do coque. Outro problema é que essa grande quantidade de gases aumenta a pressão na região das ventaneiras. Como o alto teor de voláteis é uma característica das biomassas em geral, um tratamento de torrefação consiste em aquecer o material a temperaturas em torno de $200^{\circ} \mathrm{C}$ na ausência de oxigênio - tende a diminuir o teor de voláteis e aumentar o teor de carbono fixo.

Além disso, um maior teor de hidrogênio em sua composição contribui para a redução do minério de ferro. A presença de maiores quantidades de hidrogênio pode ser benéfica para o processo, uma vez que pode atuar como um gerador de calor. $O$ hidrogênio reduz o minério de ferro de maneira menos endotérmica que o carbono, ou seja, requer menos energia para ocorrer a reação de redução. Com isso, é possível operar o alto-forno com uma temperatura de chama menor do que quando se utilizam materiais com menor teor de hidrogênio. Em contraste, o hidrogênio causa uma degradação prematura do coque no alto-forno, danificando a permeabilidade através da formação de finos dentro do reator [II].

Outro fato importante é o teor de cinzas e enxofre. A quantidade de cinza deve ser inferior a $10 \%$ para não aumentar a quantidade de escória e consequente perda de produtividade. $\mathrm{O}$ enxofre contribui da mesma forma e também contribui para a mudança de basicidade da escória. Além disso, altos teores de enxofre requerem maior gasto com processos subsequentes de dessulfuração, uma vez que o enxofre é extremamente prejudicial às propriedades mecânicas do aço.

A Tabela 2 mostra os resultados do cálculo da eficiência de combustão, seguindo a Equação I, das amostras.

Tabela 2. Eficiência de Combustão das amostras analisadas

\begin{tabular}{lcccc}
\hline \multicolumn{1}{c}{ Material } & $\begin{array}{c}\text { Taxa de Injeção } \\
\text { (kg/t de gusa) }\end{array}$ & $\begin{array}{c}\text { Eficiência de Combustão } \\
\text { (\%) }\end{array}$ \\
\hline Carvão Mineral & 80 & 90,0 & 90,2 & 90,6 \\
& 100 & 85,1 & 85,3 & 85,9 \\
& 150 & 65,1 & - & 65,9 \\
Casca da Semente & 80 & 90,7 & 90,8 & 90,6 \\
da Moringa & 100 & - & 86,0 & 85,6 \\
& 150 & 74,0 & 73,8 & 74,2 \\
20\%Casca + & 80 & 94,9 & 94,5 & 95,3 \\
80\%Carvão & 100 & 88,2 & 88,0 & 88,3 \\
& 150 & 76,3 & 72,1 & - \\
30\%Casca + & 80 & 96,0 & - & 95,4 \\
70\%Carvão & 100 & 89,8 & 90,0 & 90,1 \\
& 150 & 76,0 & 76,6 & 75,9 \\
$40 \%$ Casca + & 80 & 96,3 & 97,2 & 96,7 \\
60\%Carvão & 100 & 90,4 & 90,6 & 90,2 \\
& 150 & 78,1 & 78,5 & 78,7 \\
\hline
\end{tabular}




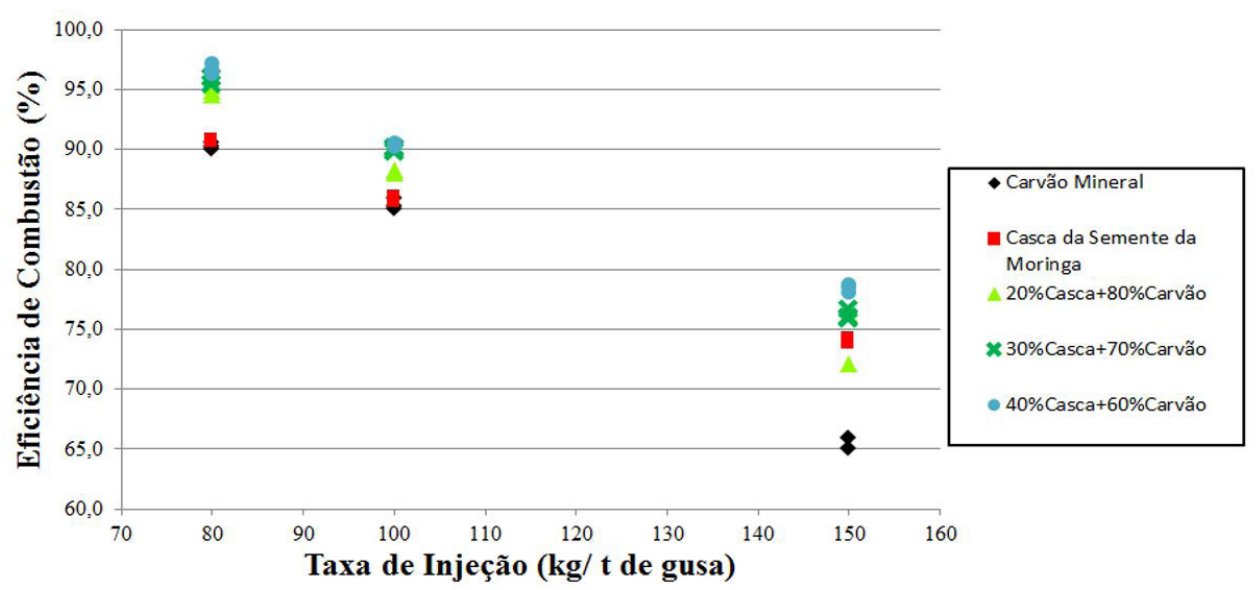

Figura 2. Taxa de combustão para diferentes taxas de injeção da casca da semente da moringa e misturas de carvão mineral.

Algumas amostras apresentaram problemas como vazamento de gás das ampolas e perda de material ao ser colocados no porta amostra, sendo assim, não foi possível calcular a eficiência de combustão.

A Figura 2 mostra os resultados obtidos no teste de simulação de injeção para as taxas de injeção de 80,100 e $150 \mathrm{~kg}$ de material por tonelada de ferro gusa produzido.

Como a casca da moringa apresenta melhor combustibilidade, devido às suas propriedades, o aumento da quantidade no carvão influencia positivamente a combustão na raceway. Este é um fato importante para considerar o uso da casca de sementes da moringa oleifera como aditivo à mistura de carvões utilizada na injeção, aumentando a taxa de combustão do material a ser injetado.

Da mesma forma, pode-se dizer que o uso da casca pura na injeção não é interessante como o uso da mistura. Como o poder calorífico é menor que a do carvão, a tendência é que a temperatura de chama diminua com o aumento da quantidade de casca na mistura de carvão. Além disso, o uso integral de biomassa exigirá uma quantidade muito maior que dificilmente poderá ser suprida com a disponibilidade do mercado atual.

A avaliação da moabilidade não foi alvo deste trabalho, porém é possível encontrar na literatura alguns trabalhos, com biomassas, onde esta propriedade é analisada. Testes feitos com bagaço de cana mostra que esta biomassa in natura possui um HGl (Hardgrove Grindability Index) de 17, valor muito baixo, mas que aumenta a medida que eleva-se a temperatura de torrefação, podendo chegar a 73 quando tratado a uma temperatura de $273^{\circ} \mathrm{C}[12]$.

Ambientalmente, o uso parcial da casca da semente da moringa pode contribuir significativamente para a redução das emissões de $\mathrm{CO}_{2}$ no alto-forno, que representa $70 \%$ de todas as emissões deste gás em uma siderúrgica [13].
Considerando que todo $\mathrm{CO}_{2}$ liberado na queima da casca é consumido durante o crescimento da moringa oleifera pelo processo de fotossíntese e que uma empresa que produz 10 mil toneladas de ferro gusa por dia injeta $150 \mathrm{~kg}$ de carvão por tonelada de metal quente. No final do dia, pode-se dizer que 4400 toneladas de $\mathrm{CO}_{2}$ são emitidas no processo de injeção de materiais pulverizados. Substituindo $40 \%$ desse carvão por casca de sementes de moringa, a emissão diária de $\mathrm{CO}_{2}$ seria de 1320 toneladas. Este resultado representa uma redução de $30 \%$ nas emissões de $\mathrm{CO}_{2}$ no processo de injeção de alto-forno.

\section{CONCLUSÃO}

As principais conclusões obtidas neste estudo foram:

- A casca da semente da moringa oleifera tem um teor de carbono, nitrogênio, enxofre, cinzas e carbono fixo mais baixo do que os carvões minerais comumente usados no processo de injeção do alto-forno;

- O poder calorífico da casca da semente da moringa oleifera é menor que o carvão mineral;

- O conteúdo de materiais voláteis, hidrogênio e oxigênio são maiores que o carvão mineral;

- A taxa de combustão da casca da semente da moringa é melhor que a do carvão, mas misturas contendo $40 \%$ de casca e $60 \%$ de carvão;

- A casca da semente da moringa pode substituir parcialmente o carvão na injeção de materiais pulverizados no alto-forno, reduzindo as emissões de $\mathrm{CO} 2 \mathrm{em} 30 \%$ neste processo. 


\section{REFERÊNCIAS}

I Oliveira DS, Xavier DSF, Farias PN, Bezerra VS, Pinto CHC, et al. Obtenção do biodiesel através da transesterificação do óleo de Moringa oleifera lam. HOLOS, 20 I 2; I:49-6I.

2 Vilaseca M, Grimau V, Bouzan C. Valorization of waste obtained from oil extraction in moringa oleífera seeds: coagulation of reactive dyes in textile effluents. Materials (Basel). 2014;7:6569-6584.

3 Suopajärvi $\mathrm{H}$, Pongrácz E, Fabritius T. The potential of using biomass-based reducing agentes in blast furnace: a review of thermochemical conversion technologies and assenssments related to sustainability. Renewable \& Sustainable Energy Reviews. 2013;25:5 I I-528p.

4 Assis CFC, Tenório JAS, Assis PS, Nath NK. Experimental simulation and analysis of agricultural waste injection as an alternative fuel for blast furnace. ACS Energy \& Fuels. 20I4;28(I I):7268-7273.

5 Gums A, Flores BD, Agra AA, Silva GLR, Vilela ACF, Osório E. Estudo das interações entre carvões no desenvolvimento plástico de misturas contendo carvão nacional. In: Anais do $48^{\circ}$ Seminário de Redução de Minérios e Matérias-primas; 2008; São Paulo. São Paulo: ABM; 2018.

6 Sánchez, C. G. Caracterização de Biomassa .Campinas: UNICAMP/Faculdade de Engenharia Mecânica, Departamento de Eng. Térmica e de Fluidos, 2008. (2o capítulo da disciplina Tecnologia da Gaseificação).

7 Oliveira RS, Assis PS, Assis CFC. Estudo da injeção de casca de eucalipto com carvão mineral em alto-forno. Tecnologia em Metalurgia, Materiais e Mineração. 2016; 13(2): I30-I 35.

8 Fragoso HAP, Pohlmann JG, Machado JGMS, Vilela ACF, Osório E. Influência dos voláteis e do tamanho de partículas de carvões na combustão em simulador de PCl. In: Anais do 48 Seminário de Redução. São Paulo: ABM; 2019. p. 383-394.

9 Rodrigues PMS, Silva PAF. Quantificação das emissões de dióxido de carbono (CO2) por veículos automotores na cidade de Boa Vista/RR-2005-20I5. In: Anais do $7^{\circ}$ Congresso Luso Brasileiro para o Planejamento Urbano, Integrado e Sustentável; 2016 Outubro 5-7; Maceió, Brazil. São Carlos: Edufscar; 2016.

10 Assis PS, Martins W, Batista C. Avanços na injeção de carvões pulverizados para sua aplicação em altos-fornos. REM: Revista Escola de Minas. 2003;56(4):28I-285.

I I Barbieri C, Ósorio E, Vilela A. Combustibility and reactivity of coal blends and charcoal fines aiming use in ironmaking. Materials Research. 2016;19(3):594-60I.

12 Tapanes N, Soler P, Santana A, Perez R, Silva N, Santos A. Tecnologias de pré-tratamento para pirólise rápida do bagaço de cana-de-açúcar: uma revisão bibliográfica. AS\&T Acta Scientiae \& Technicae. 20।8;6:36-6I.

I3 Suopajärvi H, Kemppainen A, Haapakanga J, Fabritius T. Extensive review of the opportunities to use biomass-based fuels in iron and steelmaking processes: Journal of Cleaner Production. 2017;148:709-734.

Recebido em: 17 Jun. 2019

Aceito em: 8 Dez. 2019 